\title{
Independência econômica e sexual atrás da Cortina de Ferro
}

Economic and Sexual Independence Behind the Iron Curtain

Henrique Cintra Santos ${ }^{1}$ (iD 0000-0003-1989-8992

'Universidade Federal de Santa Catarina, Programa de Pós-Graduação em História, Florianópolis, SC, Brasil. 88040-900 - ppghst@contato.ufsc.br

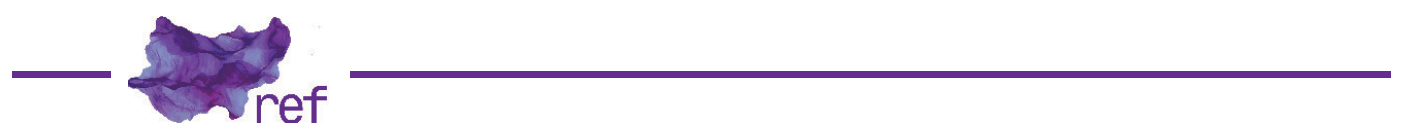

GHODSEE, Kristen.

Why Women Have Better Sex Under Socialism: And Other Arguments for Economic Independence.

New York: Nation Books, 2018.

Kristen Rogheh Ghodsee é uma professora estadunidense, vinculada ao Departamento de Antropologia da Universidade da Pensilvânia, e tem se empenhado, principalmente, em observar os impactos no que concerne o gênero a partir da transição das sociedades que viviam sob os extintos Estados socialistas para uma configuração regida pela lógica do mercado. Em sua publicação de 2018, Why Women Have Better Sex Under Socialism - And Other Arguments for Economic Independence, a autora não aponta apenas quais as condições gerais em que se encontravam as mulheres que viviam nos Estados socialistas, como também frisa a relevância de tais observações ao considerar a possibilidade de implementar tais políticas públicas nas sociedades capitalistas contemporâneas a fim de minimizar os impactos que a matriz econômica, política e social capitalista projeta sobre as mulheres.

Nos seis capítulos que seguem a introdução de seu livro, Kristen Ghodsee (2018) mescla sua argumentação junto às suas percepções de cidadã e moradora do país considerado modelo de neoliberalismo, os Estados Unidos. A autora, assim, alia fontes, bibliografias a relatos pessoais, viabilizando uma narrativa que combina o rigor científico a uma mais fluida, o que amplia seu público para além do acadêmico. Nesse sentido, percebe-se, por exemplo, uma apresentação contínua dos resultados de pesquisa intercalados com narrativas provenientes do eixo privado da autora que auxiliam em contrastar a condição das mulheres na sociedade capitalista contemporânea e no extinto bloco socialista.

Mais do que apenas desconstruir a narrativa pejorativa da Guerra Fria sobre os Estados socialistas, o trabalho de Ghodsee nos convida a examinar o transcorrido com o propósito de projetar um melhor futuro. Seu trabalho não idealiza o passado socialista ou minimiza o totalitarismo que marcou a maior parte desses regimes, mas pondera as narrativas em disputa e extrai desse jogo político entre capitalismo e socialismo, ainda pouco superado, algumas indicações para um engajamento atual.

Josie McLellan (2011), em suas análises para o caso específico da Alemanha Oriental, observou a ascensão de um discurso que defende que a unificação da Alemanha teria extinto uma vivência em sua parte socialista considerada mais feliz que a experimentada após a queda do Muro de Berlim, ou seja, a capitalista. Apesar de tal discurso estar envolto de disputas 
e idealizações relacionadas à promoção de uma memória nacional do passado socialista alemão, sua propagação não pode ser restringida à nostalgia. Como observam McLellan e Ghodsse, há algo de empírico nestes discursos. Em especial para as mulheres, a dissolução dos Estados socialistas realmente significou um esfacelamento de uma sociedade que proporcionava não apenas a oportunidade de emancipação, mas uma contínua manutenção dessa independência.

Ghodsee demonstra que os Estados socialistas, em graus diversos, observaram a necessária emancipação das mulheres através de sua inserção educacional e nos postos formais de trabalho, tanto no setor industrial quanto no de serviços. Para que tal objetivo fosse alcançado, instaurou-se não somente políticas voltadas para isso, bem como para a manutenção das conquistas alcançadas. Assim, políticas públicas como sistemas de saúde universal, de creche, de licença maternidade, entre outras, foram desenvolvidas a fim de garantir que o investimento na qualificação das mulheres pelo Estado não fosse minado pelas expectativas dos papéis de gênero, os quais ainda eram fortemente enraizados, mesmo dentro dessas sociedades.

Como demonstra Ghodsee, no ano de 1975, considerado o Ano Internacional das Mulheres na ONU, pesquisas apontavam $49,7 \%$ da força de trabalho na URSS e $43,7 \%$ no Leste Europeu era constituída por mulheres frente a $37,4 \%$ na América do Norte e apenas $32,7 \%$ na Europa Ocidental. Tal dissonância, frisa a autora, deve ser interpretada não apenas como resultado das políticas de inserção das mulheres engajadas por tais Estados, mas também as redes de apoio e assistência que garantiam sua permanência em tais posições de trabalho.

A questão da manutenção da emancipação conquistada é um dos principais pontos de comparação para Ghodsee ao refletir sobre o contexto capitalista atual, principalmente o estadunidense. A autora relata, por exemplo, como um de seus colegas de longa data teria dado preferência em contratar uma mulher, mas esta abandonou posteriormente o posto por não conseguir conciliar suas responsabilidades do trabalho com os cuidados do filho. Seu amigo atesta, então, que não "poderia ter certeza sobre nenhum empregado, mas tenho certeza que um homem não terá um bebê." (GHODSEE, 2018, p. 68, tradução nossa').

Para Ghodsee, no entanto, os efeitos divergentes provocados por ambas ideologias, capitalista ou socialista, vão além das implicações econômicas e recaem também sobre a vida privada, o desejo e o prazer. Respondendo o questionamento que nomeia o seu livro, Ghodsee aponta para a possibilidade de uma melhor realização sexual dentro das sociedades cujo sistema socialista desvencilha seus corpos da lógica mercadológica:

ao implementar políticas socialistas para aumentar as oportunidades para a empregabilidade das mulheres e liderança (através de garantias de emprego e algumas formas de cotas), assim como programas subsidiados pelo Estado como licença maternidade e creches, mulheres serão menos coagidas a vender sua sexualidade para atender suas necessidades básicas (GHODSEE, 2018, p. 172, tradução nossa²).

Mais uma vez, os alemães orientais aparecem nesse terreno como proveitosa ilustração ao atestarem, como aponta Josie McLellan (2011), que seus cidadãos teriam passado por uma transformação sexual a qual resultaria, então, em vidas sexuais mais satisfatórias que suas contrapartes capitalistas. Ghodsee argumenta que tal crença era sustentada pelos pesquisadores alemães socialistas a partir da justificativa de que "o sistema socialista melhorou a vida sexual das pessoas precisamente porque sexo não era mais uma mercadoria a ser comprada e vendida no livre mercado." (GHODSEE, 2018, p. 154, tradução nossa ${ }^{3}$ ). Feitas as ressalvas frente a tais assertivas generalizantes, a dissolução do aspecto mercadológico ligado ao sexo foi um resultado significativo das políticas socialistas - como é possível observar em uma pesquisa feita na Hungria nos anos $1970 \mathrm{em}$ que as pessoas eram expostas a oito narrativas e deviam classificá-las em ordem do que mais as agradavam até o que mais discordavam. Entre tais narrativas havia temas como a manutenção da virgindade até o casamento, a homossexualidade masculina, prostituição, entre outros. A pesquisa mostrou que a maioria, mesmo frente à homofobia generalizada nessa sociedade na época, colocou a prostituição em último lugar, o que ilustra o desconforto dessa sociedade frente à mercantilização do sexo.

A fim de não se restringir às dinâmicas atrás da Cortina de Ferro, Ghodsee também introduz um relato atual de um amigo, para quem seu antigo casamento teria sido mantido por interesse da contraparte em garantir uma estabilidade econômica. O sujeito se viu perplexo ao supor que caso desejasse ter uma relação com alguém que o quisesse por sua personalidade, e não pelo o que possuía, deveria procurar, talvez, uma mulher independente. Para o amigo, relata a autora, isso era um desafio, já que a emancipação feminina econômica significa um jogo do

\footnotetext{
' No original: "I can't be sure of anything about any employee, but I can be certain that a man won't have a baby." 2 No original: "By implementing socialist policies to increase opportunities for women's employment and leadership (through job guarantees or some form of quotas) as well as state-supported programs for parental leave and subsidized child care, women will be less coerced into selling their sexuality to meet their basic needs."

${ }^{3}$ No original: "the socialist system improved people's sex lives precisely because sex was no longer a commodity to be bought and sold on the open market."
} 
desejo totalmente díspar daquele em que o sexo se dá atrelado a uma lógica mercadológica e - para o homem capitalista - uma empreitada fora dessa perspectiva se faz bastante inóspita. Desculpando-se por talvez soar ingênua, Ghodsee propõe que possivelmente as relações que se dão exteriores às trocas entre desejo/sexo/mercadoria são "no geral mais honestas, autênticas e, simplesmente, melhores." (GHODSEE, 2018, p. 174, tradução nossa4).

Ghodsee enxerga em sua argumentação não uma glorificação do passado socialista, mas uma forma de "compreender como o capitalismo afeta nossas experiências mais íntimas ao olhar para as sociedades em que as forças do mercado tinham um menor impacto." (GHODSEE, 2018 , p. 143, tradução nossa ${ }^{5}$ ). Além disso, em um mundo globalizado no qual o neoliberalismo avança ostensivamente e as políticas sociais subsidiadas pelo Estado são colocadas cada vez mais como um gasto injustificável, observar tal passado não se faz apenas necessário, mas uma fonte de inspiração para políticas futuras - o que não significa ignorar as atrocidades cometidas por tais Estados no passado ou então rogar por um retorno a tais modelos políticos e econômicos.

Talvez a maior limitação da obra de Ghodsee foi ter enxergado o necessário ponto de contrapartida como sendo, quase que exclusivamente, os Estados Unidos. Países fora do extinto bloco socialista como a França, Inglaterra e o Brasil vêm presenciando uma gradual guinada à extrema-direita e uma intensificação dos discursos que negam qualquer aspecto positivo dos antigos Estados socialistas. Apesar de ser compreensível o foco na sociedade estadunidense, visto a nacionalidade e atuação de Ghodsee, observações sobre outros países seriam bastante pertinentes. Tais apontamentos poderiam frisar que não apenas o expoente do neoliberalismo, os EUA, mas as políticas globais, cada vez mais neoliberais, podem se beneficiar do resgate de tais experiências realizadas pelos antigos países atrás da Cortina de Ferro.

Como afirma a autora, "ainda são as pessoas comuns que podem levar a história adiante. Ação coletiva coordenada pode ter um impacto enorme no mundo" (GHODSEE, 2018, p. 185, tradução nossa ${ }^{6}$ ). E Why Women Have Better Sex Under Socialism é não apenas uma fonte de inspiração para a ação coletiva, mas também para mudanças que apontam para um futuro cujas possibilidades vão além da lógica neoliberal vigente.

\section{Referências}

GHODSEE, Kristen. Why Women Have Better Sex Under Socialism: And Other Arguments for Economic Independence. New York: Nation Books, 2018.

MCLELLAN, Josie. Love in Time of Communism: intimacy and sexuality in the GDR. Cambridge: Cambridge University Press, 2011.

Henrique Cintra Santos (henriquecintra@outlook.com) é doutorando no Programa de Pós-Graduação em História da Universidade Federal de Santa Catarina (UFSC), na linha de pesquisa Histórias Entrecruzadas de Subjetividades, Gênero e Poder. Dedica-se às questões de gênero e sexualidade, com enfoque na História Comparada dos movimentos LGBTQ+ no Brasil e na Alemanha.

\footnotetext{
${ }^{4}$ No original: "are generally more honest, authentic, and, well, just better."

${ }^{5}$ No original: "understand how capitalism affects our most intimate experiences by looking to societies in which market forces had less of an impact."

${ }^{6}$ No original: "it is still ordinary people who can push history forward. Coordinated collective action can have a huge impact on the world."
} 
COMO CITAR ESTE ARTICO DE ACORDO COM AS NORMAS DA REVISTA

SANTOS, Henrique Cintra. "Independência econômica e sexual atrás da Cortina de Ferro". Revista Estudos Feministas, Florianópolis, v. 29, n. 2, e72269, 2021.

\section{CONTRIBUIÇĀO DE AUTORIA}

Não se aplica.

\section{FINANCIAMENTO}

O presente trabalho foi realizado com apoio da Coordenação de Aperfeiçoamento de Pessoal de Nível Superior - Brasil (CAPES) - Código de Financiamento 001.

\section{CONSENTIMENTO DE USO DE IMAGEM}

Não se aplica.

\section{APROVAÇĀO DE COMITÊ DE ÉTICA EM PESQUISA}

Não se aplica.

\section{CONFLITO DE INTERESSES}

Não se aplica.

\section{LICENÇA DE USO}

Este artigo está licenciado sob a Licença Creative Commons CC-BY 4.0 International. Com essa licença você pode compartilhar, adaptar, criar para qualquer fim, desde que atribua a autoria da obra.

\section{HISTÓRICO}

Recebido em 19/03/2020

Revisões requeridas em 27/05/2020

Aprovado em 30/06/2020 